the past 25 years by my colleagues at the National Hospital and myself. Long-term follow-up of patients treated for facial spasm by the various forms of surgery of the facial nerve alone has in our experience shown that unless its continuity is interrupted the spasm returns to its former or a more severe state in most patients after a varying period of time, at times as much as 2-3 years, usually much less. Selective division of the terminal branches of the facial nerve by the method advocated by Reynolds, ${ }^{1}$ Nosik, ${ }^{2}$ and $\mathrm{McCabe}^{3}$ has the advantage of producing relief of the spasm for, in most cases, a longer period than after partial division of the nerve trunk, and if a palsy results it is usually limited to the muscles supplied by the nerve branches. In many of the patients the spasms are so severe and widespread that operations such as these are not practical.

In the past 3-4 years several patients with severe unilateral spasm have been treated by section of the seventh nerve close to its division in the parotid gland and anastomosing the distal portion to the hypoglossal nerve. Though the anastomosis was successful in restoring facial movement, in the first two cases the spasm returned within a year of operation owing to growth of the seventh nerve fibres into the anastomosis. This was easily remedied by a short second operation to evulse the facial nerve fibres from the facio-hypoglossal anastomosis and ligate the proximal section of the facial nerve with silk thread.-I am, etc.

M. SPENCER HARRISON

The National Hospital,

Queen Square,
London W.C.1

1 Reynolds, D. H., Smith, J. L., and Walsh, T. J., Trancactions of the American Academy of 656.

2 Nosik, W. A. and Weil, A. A., Fournal of Neurosurgery 1956, 13, 596.

McCabe, B. F., Annals of Otology, Rhinology and Laryngology, 1970, 79, 252.

\section{Radiotherapy and Carcinoma of the Parotid}

SIR,-My colleagues and I have established ${ }^{1}$ that a high percentage of carcinomas of the parotid arise in pleomorphic adenomas, primary or recurrent. The only clear predisposing factor in our series was the presence of the pleomorphic adenoma for a long time, histories of 10-20 years and even much longer being common. More recently, however, Saksela et al. ${ }^{2}$ have reported from Helsinki that three out of six patients with clinical and histological evidence of carcinoma superimposed on a pleomorphic adenoma had been irradiated 8-24 years previously for a parotid tumour not surgically removed, these being the only cases of pleomorphic adenoma so treated. In view of the suggestion that the radiotherapy may have exercised a causative influence on the development of the carcinoma, two previously unreported personal cases are of interest.

In 1954 I saw a man aged 27 with a recurrence of a pleomorphic adenoma of the left parotid following enucleation. I advised conservative parotidectomy, which was refused, and the patient subsequently had a full course of radiotherapy. I next saw him in 1960, when he presented with an enormous, rapidly growing mass in the left parotid region, extensively infiltrating outside the anatomical limits of the parotid.
Exploration at another hospital established the diagnosis of carcinoma superimposed on a pleomorphic adenoma, and not long afterwards he died from generalization of the disease.

The second case is that of a man aged 30 who presented in November 1971 with a history that two years previously he had noticed a lump in the right parotid. A technically uneventful total conservative parotidectomy was performed for what proved to be a tumour lying in the subfacial parotid deep to the facial nerve. Macroscopically, the tumour was a typical lobulated pleomorphic adenoma. Microscopically, the diagnosis of pleomorphic adenoma was confirmed, but there was "one area of malignant change where carcinoma infiltrates the capsule." The patient was given a course of radiotherapy and remains well to date. After the operation the patient mentioned incidentally that at the age of 11 , following recurrence of his adenoids after surgery, he was given a course of radiotherapy through two lateral portals which cleared the trouble up. Conclusions must be guarded from what, so far as I am aware, is a unique case, but the question arises whether this is a comparable sequence to the well-established development of carcinoma of the thyroid following irradiation of the thymus in childhood.-I am, etc.

London W.1

David Patey

1 Patey, D. H., Thackray, A. C., and Keeling, 2 D. H., British fournal of Cancer, 1965, 19, 712 ., Acta Otolaryngologica, 1970, 70, 62.

\section{Dr. F. A. Cook's Diaries}

SIR,-Your readers may wish to know of the existence of notes and letters by $\mathrm{Dr}$. Frederick A. Cook that are preserved in the Center for Polar Archives, Washington D.C. My own interest in them stems from research which led me to examine women reported to have significantly differen fecundities, among them the Hutterites in Canada and, more recently, the Eskimos. Most medical papers ${ }^{12}$ on Eskimo fertility and related matters are based on or opposed to the observations published by Cook, ${ }^{34}$ who studied the Arctic Highlanders (Eskimos of north-west Greenland) while serving with Robert E. Peary's North Greenland expedition, 1891.

Cook's later claims to have been the first to ascend Mount McKinley and to attain the North Pole have been the subjects of violent controversy, and a generally unfavourable press has caused his other and undoubted achievements to be neglected. was therefore delighted to learn, through the Scott Polar Research Institute, of Cook's papers in Washington, and I examined them in June 1972 while in that city. They form part of the Peary Papers, a voluminous collection that includes diaries, letters, notes, etc., of other members of Peary's many Arctic expeditions. ${ }^{5}$ Some of Cook's notes describe the Arctic Highlanders and a census (partly Cook's work) for the years 1891-6 contains detailed personal and genealogical information on some 230 primitive Eskimos. There is also a photographic index and remarks in the notes to indicate that some hundreds of photographs had been taken of Eskimos during this period. The photographs are in the vaults of the National Geographic Society, and I was permitted limited access to them. Clearly they are somehow related to the census forms, and the photographs themselves - nude frontal, rear, and side views-are of great anthropological and medical interest.

Cook's diaries have not yet been found, however, and I hope some reader may have advice or suggestions for locating them or may be able to supply other information related to the subject.-I am, etc.,

GEOFFREY DOVE

London W.14

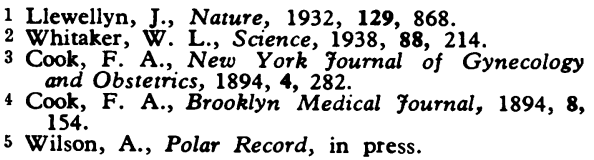

Hypotension and Methylmethacrylate Cement

SIR,-Drs. G. T. G. Brittain and D. J. Ryan (16 December, p. 667) state that "a careful surgical appraisal of the degree of plasticity of the [acrylic] cement prior to its insertion [into the femoral shaft during arthroplasty], preceded by a careful technique of preparation, are the important factors which really reduce subsequent hypotension to a minimum." Such a dogmatic assertion is unsatisfactory and bound to cause confusion. The importance of aeration of the mixture to allow excess monomer to evaporate into the room air rather than to diffuse into the patient's blood is obvious, but there is no evidence to support the contention that this is the all-important factor. In two clinical studies $^{12}$ adequate time was allowed for evaporation of excess monomer, but hypotension still occurred, as did two episodes of card'ac arrest in cases in which the established technique of mixing was used. ${ }^{3}$ It is much more likely that the freedom from cardiovascular complications of the patients at Wrightington is due to the care with which their medical fitness for operation is assessed. This has already been stressed by Charnley and his other colleagues. ${ }^{4}$

Confusion may also arise because of a discrepancy concerning the effect of hypotensive anaesthesia on the fall in blood pressure which follows the use of acrvlic cement. Drs. Brittain and Ryan state that induced hypotensive anaesthesia does not modify the fall in blood pressure even though Charnley (observing the same group of patients) has asserted that such a technique regularly abolishes this effect of the cement. ${ }^{5}$ These two statements are clearly incompatible and it will be important to learn which is correct.-I am, etc.,

St. Bartholomew's Hospital,

RICHARD H. ELLIS

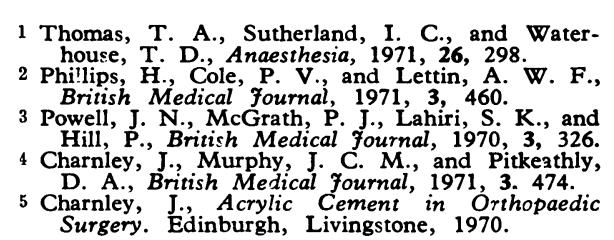

ABO Blood Groups and Sex Ratio at Birth

SIR,-I have shown ${ }^{1}$ that in the aggregate of the 15 series of white newborn babies and their mothers reported in the period 1924-72 there exists in respect of the ratio 
Sex Ratio of White Newborn Babies, 1924-72, by their own and their Mothers' ABO Blood Group

\begin{tabular}{|c|c|c|c|c|c|c|c|c|c|c|c|}
\hline \multicolumn{2}{|c|}{ Blood Group } & \multicolumn{3}{|c|}{$\begin{array}{c}\text { Aggregate of } 15 \\
\text { White Series } \\
\text { (1924-72) }\end{array}$} & \multicolumn{3}{|c|}{$\begin{array}{l}\text { White Series } \\
\text { of Maraz } \\
\text { et al. }(1972)\end{array}$} & \multicolumn{4}{|c|}{ Total } \\
\hline Mothers & Babies & $\begin{array}{c}\text { Male } \\
\text { Babies }\end{array}$ & $\begin{array}{c}\text { Female } \\
\text { Babies }\end{array}$ & $M / F$ & $\begin{array}{c}\text { Male } \\
\text { Babies }\end{array}$ & $\begin{array}{l}\text { Female } \\
\text { Babies }\end{array}$ & $M / F$ & $\begin{array}{c}\text { Male } \\
\text { Babies }\end{array}$ & $\begin{array}{l}\text { Female } \\
\text { Babies }\end{array}$ & $\mathbf{M} / \mathbf{F}$ & $M / F$ \\
\hline$\overline{\mathrm{AB}}$ & $\begin{array}{c}A \text { or } B \\
A B\end{array}$ & $\begin{array}{l}824 \\
141\end{array}$ & $\begin{array}{l}647 \\
135\end{array}$ & $\begin{array}{l}1.27 \\
1.04\end{array}$ & $\begin{array}{l}93 \\
23\end{array}$ & $\begin{array}{l}67 \\
18\end{array}$ & $\begin{array}{l}1 \cdot 39 \\
1 \cdot 28\end{array}$ & 1,081 & 867 & $1 \cdot 25$ & \multirow{2}{*}{1.07} \\
\hline A & $\underset{A}{O \text { or }} \underset{A B}{\text { or } B}$ & $\begin{array}{l}3,496 \\
5,633\end{array}$ & $\begin{array}{l}3,083 \\
5,560\end{array}$ & $\begin{array}{l}1 \cdot 13 \\
1.01\end{array}$ & $\begin{array}{l}191 \\
326\end{array}$ & $\begin{array}{l}195 \\
349\end{array}$ & $\begin{array}{l}0.98 \\
0.93\end{array}$ & 9,646 & 9,187 & 1.05 & \\
\hline $\mathbf{O}$ & $\underset{O}{A \text { or } B}$ & $\begin{array}{l}3,291 \\
7,520\end{array}$ & $\begin{array}{l}3,194 \\
6,839\end{array}$ & $\begin{array}{l}1.03 \\
1 \cdot 10\end{array}$ & $\begin{array}{l}155 \\
227\end{array}$ & $\begin{array}{l}146 \\
168\end{array}$ & $\begin{array}{l}1.06 \\
1.35\end{array}$ & 11,193 & 10,347 & 1.08 & \multirow{2}{*}{1.08} \\
\hline$\overline{\mathbf{B}}$ & $\underset{B}{\mathrm{O} \text { or }} \underset{\mathrm{B}}{\mathrm{AB}}$ or $\mathrm{A}$ & $\begin{array}{l}1,497 \\
1,243\end{array}$ & $\begin{array}{l}1,467 \\
1,075\end{array}$ & $\begin{array}{l}1.02 \\
1 \cdot 16\end{array}$ & $\begin{array}{l}134 \\
119\end{array}$ & $\begin{array}{r}156 \\
97\end{array}$ & $\begin{array}{l}0.86 \\
1.23\end{array}$ & 2,993 & 2,795 & 1.07 & \\
\hline \multicolumn{2}{|c|}{ Total } & 23,645 & 22,000 & $1 \cdot 07$ & 1,268 & 1,196 & 1.06 & 24,913 & 23,196 & 1.07 & 1.07 \\
\hline
\end{tabular}

of male to female babies a dichotomy between, on the one hand, mothers of blood groups $B$ and $O$, and, on the other hand, mothers of blood groups $\mathrm{A}$ and AB. Thus babies of $\mathbf{B}$ mothers in this aggregate have a higher male/female ratio if of the same group as their mother than if of a different group (P<0.05), and this is true also for babies of $\mathrm{O}$ mothers $(P<0.05)$. In sharp contrast, on the other hand, babies of A mothers in the same aggregate have a lower male/female ratio if of the same group as their mother than if of a different group $(P<0.0005)$, and this is true also for babies of $\mathrm{AB}$ mothers $(\mathrm{P}>0 \cdot 1)$.

It has now transpired that the aggregate referred to was incomplete in that a Hungarian series of 2,464 cases $^{2}$-a series compiled in another connexion-was reported a few weeks before the appearance of the communication cited. ${ }^{1}$ Examination shows that this new series likewise exhibits the differences listed, as may be seen from the accompanying table. This fact increases the possibility that the dichotomy described may be a real one, but proof (or disproof) of its reality must await the publication of further large series.

I am grateful for helpful comment from Dr. H. B. M. Lewis and Professors D. F. Kerridge and E. B. Ford.-I am, etc.,

T. M. Allan

Blood Transfusion Service,

Royal Infirmary,

1 Allan, T. M., British Medical fournal, 1972, 2, Mará, A., Keserü, T., Kaiser, G., Annus, J., and Szontágh, F., Orvosi Hétilap, 1972, 113,

\section{Hazardous Wastes}

SIR,-Your leading article (30 December, p. 746) refers to the fact that hospitals are Crown property and therefore may be exempt from the provisions of Acts which legislate about waste disposal.

Most hospital waste must be destroyed by incineration and the increasing use of disposable materials has completely altered the composition of refuse during the last five years. Hospital engineers should be provided with equipment which enables them to comply with the recommendations of the Technical Committee on the Disposal of Solid Toxic Wastes. ${ }^{1}$ In its report this committee laid down that the first statutory requirement of an incinerator is that the furnace should be capable of being operated smokelessly and that when noxious gases such as hydrogen chloride are emitted a water or soda scrubber and a cooling system should be employed.

The time has come for hospitals to comply strictly with all Acts designed to minimiz air pollution and it is morally indefensible for them to be able to evade their responsibilities by virtue of their being Crown property.-I am, etc.,

Winchester, Hants

P. J. HORSEY

1 Ministry of Housing and Local Government and Solid Toxic Wastes. London, H.M.S.O., 1970.

\section{Contraception and Infertility}

SIR,-Dr. K. L. Oldershaw and Mr. J. M. Brudenell (28 October, p. 233) state that "The best prophylaxis [of legal abortion and therefore of post-abortal sterility] ... remains the prevention of unplanned pregnancy by adequate contraceptive measures.

This opinion is frequently expressed in your columns, in Parliament, and in the booklet Unplanned Pregnancy put out by the Royal College of Obstetricians and Gynaecologists.

Everyone would be happy if this simple concept of human behaviour were true, but the reverse seems to be the case. As a scientific discipline we should fundamentall be concerned with facts. The evidence in Britain, as well as in every other Western country, shows that as contraception is disseminated the abortion rate, instead of going down, actually goes up.

There are two probable explanations for this interesting phenomenon, which is analagous to the encouragement of alcoholism by that other simple remedy, prohibition. One is that legal abortion and official contraception are both stimulants of sexual activity, whether within or outside of marriage. The other is philosophical-both are antinatalist (to use the International Planned Parenthood Federation term), and therefore one cannot reasonably be expected to act in opposition to the other. - I am, etc.,

Auckland, New Zealand

H. P. DUNN

\section{Tubal Sterilization and its Reversal}

SIR,-Increasingly, women submit to tubal sterilizing operations, and seemingly the vast majority are well pleased, but a few later want their fertility restored.

I would plead that tubal sterilization should not be undertaken lightly, particularly when the patient is very young, for ordinarily this procedure leads to irrevocable infertility.
However, if after due consideration and a full explanation to the patient it is decided to sterilize by a tubal operation, then it should be performed without needless mutilation. It is sufficient to divide the oviducts about $1 \mathrm{~cm}$ from the uterus, to ligate the medial stump with catgut, and to bury it behind the round ligaments. The cut end of the outer portion of the tube should be ligated with thread and fixed in front of round ligament, so that there is physical barrier between them to prevent a istulous connexion from developing. Afte such an operation it is generally quite eas to perform tubo-tubal anastomosis and to restore the oviduct to a near normal state with a $70 \%$ prospect of restoring fertility, which is virtually impossible after operations such as laparoscopic diathermy coagulation.

There was a time when radicality was the surgeons' aim, and indeed it may be very proper in an older patient, when vaginal hysterectomy is often the procedure of choice. For the young patient, however, I maintain that the surgeon should sterilize by an elegant technique that allows a prospect of restoring fertility by tubo-tubal anastomosis. The sterilizing operation that I have described has been practised at Oxford for over 30 years and offers an excellent opportunity for reversal. Moreover, tubotubal anastomosis is in every way superior to the old utero-tubal implantation operation that has been hitherto the operation of choice in England and which in fact gave very disappointing results. - I am, etc.,

John Radcliffe Hospital

E. A. Williams Oxford

\section{Consultant Negotiations}

SIR,-Many correspondents who are critical of our contract proposals have questioned the competence of the Central Committee for Hospital Medical Services to negotiate on behalf of consultants. Recently the Regional Hospitals' Consultants and Specialists Association has invited those of its members (including myself) who belong to the B.M.A. to indicate whether they would prefer the R.H.C.S.A. to negotiate on their behalf and whether they would be prepared to resign from whichever association they did not wish to represent them in negotiations if it became necessary for the purpose of obtaining negotiating rights.

The R.H.C.S.A. is attempting to force the issue because the C.C.H.M.S. has refused its request for a voting seat on the C.C.H.M.S. Negotiating Subcommittee. I could understand the reasons for this if regional consultants were a minority group on this important subcommittee; but they are not. They outnumber all the other doctors on the subcommittee put together. If this absolute majority were further increased, claims for separate seats by other organizations representing those hospital doctors whose representatives are in a minority on the committee would be impossible to resist, and an unwieldy and divided negotiating body would result.

I could also understand the reasons if the policies on pay and conditions of service of the C.C.H.M.S. were to the disadvantage of regional consultants; but they are not. In recent memoranda of evidence to the Review Body the B.M.A. has asked for larger increases in the remuneration of the 